\title{
An exploration of Canadian emergency physicians' and residents' knowledge of computed tomography radiation dosing and risk
}

\author{
David Barbic, MD, MSc*; Skye Barbic, $\mathrm{PhD}^{\dagger}$; Jerrald Dankoff, $\mathrm{MD}, \mathrm{CM}^{\ddagger}$
}

\section{ABSTRACT}

Objective: The objective of this study was to measure the current knowledge of Canadian emergency physicians and emergency medicine residents regarding computed tomography $(\mathrm{CT})$ radiation dosing and its associated risks.

Methods: Three focus groups were conducted as the qualitative element of this study. Cognitive debriefing was carried out to ensure the validity and reliability of the focus group findings and to aid with survey development. A 26item electronic survey was developed and pilot tested for distribution to the membership of the Canadian Association of Emergency Physicians.

Results: Eighteen emergency medicine physicians and three emergency medicine residents participated in the focus groups. Four major themes emerged: 1) physician knowledge of risks associated with CT, 2) risk management strategies, 3) communication, and 4) knowledge translation. The survey response rate was $49.8 \%$ (638 of 1,281). The mean respondent age was $40.9 \pm 9.9$ years, and $70.7 \%$ were male. Of all respondents, $82.5 \%$ were actively practicing attending physicians, $56.4 \%$ of all respondents practiced in urban academic emergency departments, and the average time practicing was $10.7 \pm 9.6$ years. Radiography and CT were correctly identified by $92.2 \%$ and $95.1 \%$ of respondents, respectively, as sources of ionizing radiation, whereas magnetic resonance imaging and ultrasonography were selected by $1.0 \%$ and $0.5 \%$, respectively. With respect to the lifetime attributable risk (LAR) of malignancy due to CT, $82.2 \%$ of participants correctly identified that abdominal CT increases the risk of cancer by 0.2 to $2 \%$, whereas $51.3 \%$ correctly identified that the LAR increases twofold in a 7year-old boy. When asked to identify populations at risk for potential harm due to ionizing radiation, $92.2 \%$ of respondents identified children, $80.3 \%$ identified pregnant women, and $71.4 \%$ identified women of reproductive age. A minority $(37.2 \%)$ reported communicating the potential risks of $\mathrm{CT}$ to a majority of their patients. Electronic platforms were identified by $74.8 \%$ of respondents as their preferred method of knowledge translation on this topic.

Conclusions: Canadian emergency medicine physicians and emergency medicine residents demonstrated identifiable gaps in knowledge surrounding CT radiation dose and risk.

\section{RÉSUMÉ}

Objectif: L'étude visait à mesurer les connaissances actuelles des médecins d'urgence et des résidents en médecine d'urgence au Canada en ce qui concerne les doses de rayonnement émis par la tomodensitométrie (TDM) et les risques associés.

Méthode: Trois groupes de discussion ont été formés à titre d'élément qualitatif de l'étude. Nous avons procédé à un bilan cognitif afin de nous assurer de la validité et de la fiabilité des conclusions auxquelles en étaient arrivés les groupes de discussion, et de faciliter l'élaboration de l'enquête. Un questionnaire électronique en 26 points a été élaboré, puis soumis à un essai pilote en vue de sa distribution aux membres de l'Association canadienne des médecins d'urgence.

Résultats: Dix-huit médecins d'urgence et trois résidents en médecine d'urgence ont participé aux groupes de discussion. Se sont dégagés des échanges quatre grands thèmes: 1) les connaissances des médecins concernant les risques associés à la TDM; 2) les stratégies de prise en charge des risques; 3) les communications; et 4) I'application des connaissances. Le taux de réponse à I'enquête a atteint $49.8 \%$ (638 membres sur 1281). L'âge moyen des répondants était de $40.9 \pm 9.9$ ans, et $70.7 \%$ d'entre eux étaient des hommes. Par ailleurs, $82.5 \%$ des répondants se sont déclarés médecins traitants en pratique active; $56.4 \%$ des participants exerçaient dans des services d'urgence d'hôpitaux universitaires en milieu urbain, et la durée moyenne de la pratique s'élevait à $10.7 \pm 9.6$ ans. La radiographie et la TDM ont été relevées correctement par $92.2 \%$ et $95.1 \%$ des répondants,

From the Department of Emergency Medicine, Sunnybrook Health Sciences Centre, Toronto, ON; †Social Aetiology of Mental IIIness Program, Centre for Addiction and Mental Health, Toronto, ON; and ${ }^{\ddagger}$ Emergency Department, Jewish General Hospital, Montreal, QC.

Correspondence to: Dr. David Barbic, Department of Emergency Medicine, Sunnybrook Health Sciences Centre, Toronto, ON M4N 3M5; david.barbic@gmail.com.

This article has been peer reviewed. 
respectivement, comme sources de rayonnement ionisant, tandis que l'imagerie par résonance magnétique et l'échographie ont été relevées par $1.0 \%$ et $0.5 \%$ des participants, respectivement. En ce qui concerne le risque attribuable à vie (RAV) de cancer dû à la TDM, $82.2 \%$ des répondants ont indiqué correctement que la TDM abdominale augmentait le risque de cancer de 0.2 à $2 \%$, et $51.3 \%$ des participants ont indiqué correctement que le RAV était multiplié par deux chez un garçon de 7 ans. Pour ce qui est des groupes de patients susceptibles de subir des lésions attribuables au rayonnement ionisant, $92.2 \%$ des répondants ont indiqué les enfants; $80.3 \%$, les femmes enceintes; et $71.4 \%$, les femmes en âge de procréer. Une minorité (37.2\%) de participants a indiqué faire part des risques de la TDM à la majorité des patients. Enfin, $74.8 \%$ des répondants ont indiqué qu'ils préféraient les moyens électroniques comme outil d'application des connaissances dans le domaine.

Conclusions: L'enquête a mis en évidence des lacunes bien définies en matière de connaissances sur les doses de rayonnement émis par la TDM et les risques associés, parmi les médecins d'urgence et les résidents en médecine d'urgence au Canada.

Keywords: computed tomography, imaging, safety
The use of computed tomography (CT) in emergency medicine has grown dramatically in the last decade, ${ }^{1-5}$ driven in part by the rapid and accurate diagnostic information it can provide to the emergency physician. ${ }^{6-9}$ The potential cancer risks associated with CT imaging should be of importance in the decision making by emergency physicians. ${ }^{10-13}$ Published estimates place the population burden of malignancy due to CT imaging between 0.4 and $2 \%$ of all cancers. ${ }^{12}$ Evidence suggests that patients are not aware of these risks and do not feel that the risks associated with CT are clearly communicated to them..$^{4,14}$

Emergency physicians may benefit from a clear, accurate, and consistent method of communicating this risk to their patients and families. Indeed, there has been a recent call to adopt guidelines that all imaging facilities use some form of active information process describing the risks of medical radiation to the patient. ${ }^{11}$ At the present time, there are limited data on emergency physicians' knowledge of radiation risk from CT, including three studies that suggest this knowledge to be poor. ${ }^{14-16}$ More information is needed to clarify where this gap in knowledge rests, and what tailored training strategies are needed to acquire and apply this knowledge.

The global objective of this study was to describe emergency physician knowledge of CT radiation risk and to identify solutions for the improvement and application of new knowledge into practice. The specific objectives of the study were 1) to explore the current state of knowledge of Canadian emergency medicine attending physicians and residents regarding CT radiation dosing and its associated risks and 2) to identify a strategy for acquiring and applying this knowledge for use in clinical decision making in the emergency department (ED).

\section{METHODS}

\section{Study design}

This study had three phases: 1) focus groups, 2) survey development and cognitive debriefing, and 3) administration of the online, cross-sectional survey to investigate emergency medicine physician and emergency medicine resident knowledge of CT radiation dosing and risks. This study received approval from the Institutional Review Board of the Jewish General Hospital, Montreal, Quebec.

\section{Focus groups}

Three semistructured focus groups were conducted with a convenience sample of emergency medicine physicians and emergency medicine residents from the McGill University Health Centre and Jewish General Hospital. The objective of the focus groups was to explore physician knowledge on CT radiation dosing and risk. We drew from a diverse range of settings, including a level I trauma centre, a quaternary care academic centre, a tertiary care pediatric hospital, and a university-affiliated community hospital. The data were used as a foundation for the survey development and to validate the survey results. Based on these focus groups, we prespecified the best (correct) answer for survey questions 13 through 17 regarding lifetime attributable risk (LAR), risk groups, and relative radiation exposure.

All focus groups were conducted by the principal investigator (D.B.). A brief demographic questionnaire was administered to and completed by all participants prior to the start of the focus group. The focus group leader followed a semistructured interview guide to tailor the discussion to the study objectives. ${ }^{17}$ Questions were centred around physicians' knowledge 
of radiation risks, strategies employed to minimize patient risk from CT radiation, considerations regarding special populations, communication strategies with patients and families, information resources, and opinion regarding preferred knowledge translation on this topic. All focus groups were audio recorded and transcribed. ${ }^{17}$ After each session, qualitative analyses were conducted using an iterative process guided by grounded theory. ${ }^{18}$ Grounded theory is a commonly used strategy in qualitative research in which theories evolve during the actual research process through a continuous interplay between analysis and data collection. ${ }^{18}$ Transcripts were coded by two authors (D.B., S.B.) and were reviewed line by line until concepts emerged, and a code was applied. After full review of the transcripts, concepts were compiled and collapsed into themes and then compared to develop an understanding of their interpretation. ${ }^{17,19}$ Focus groups continued to be held until no new themes emerged, a concept known as thematic saturation. ${ }^{17}$ To ensure the credibility, transferability, reliability, and confirmability of the results, a member check was performed. ${ }^{19}$ Member checking is when data, interpretations, and conclusions are tested with members of the groups from whom the data were originally obtained. ${ }^{17,19}$

\section{Survey development and cognitive debriefing}

The survey was designed specifically for the purposes of this study. Based on the information provided from the focus groups, a 26-item survey was developed. The survey was tested with six emergency medicine attending physicians and residents using cognitive debriefing. Cognitive debriefing involves testing the survey on a small group of relevant participants to test alternative wording and to check understandability, interpretation, and cultural relevance. ${ }^{17}$ The participants for this part of the study read each item and answered the survey as per the initial directions. Modifications to both item content and directions were made at this stage to ensure the clarity and competence of the text. Once modifications were approved by all six participants, the study proceeded to the next stage.

\section{Survey administration}

In February 2010, a membership list of active members was obtained from the Canadian Association of Emergency Physicians (CAEP). Emergency medicine attending physicians and residents were emailed an invitation to participate in the study. To be eligible to participate in this study, emergency medicine attending physicians and residents had to have been practicing or training for at least 1 year, speak English, and be able to provide informed written consent. Retired physicians and medical students were not able to proceed beyond the first page of the survey and complete demographic and knowledge answers. Participants were asked to refrain from discussing the survey with peers to avoid contamination and from using reference materials when answering the survey and were not offered any financial incentive to participate.

The electronic survey was administered using a commercial online survey program (SurveyMonkey). The Dillman tailored design method for mail and Internet surveys was employed. ${ }^{20}$ Three recruitment emails, spaced approximately 2 weeks apart, were distributed.

\section{Data analysis}

Data from completed surveys were collated using Excel (Microsoft, Redmond, WA) and before analysis using $S A S$ version 9.2 (SAS Institute, Cary, NC).

\section{RESULTS}

\section{Focus groups}

Twenty-one emergency physicians (18 attending physicians and 3 residents) from the McGill University Health Centre and Jewish General Hospital participated in this part of the study. Three focus groups were conducted, with an average of seven participants in each group (range 3-11). The mean age of the participants was $39.5 \pm 9.6$ years (range $27-59$ years), and $38 \%$ were female. Four themes emerged from the focus groups:

1. Physician knowledge about the quantitative risks associated with CT dosing is limited.

2. Risk management strategies vary depending on specific patient populations (children, women of reproductive age, or pregnant women).

3. Direct communication with patients about the risks associated with CT is rare.

4. Emergency physicians have a desire to learn more about CT dosing and risks.

Table 1 lists representative quotations from the focus group sessions. 


\begin{tabular}{|c|c|}
\hline Concept & Quotations \\
\hline \multirow[t]{2}{*}{ Provider knowledge } & $\begin{array}{l}\text { 1. I think we all know that there is a certain unknown risk, but we don't know which CT scans are worse } \\
\text { or which are better. }\end{array}$ \\
\hline & $\begin{array}{l}\text { 2. I have to admit, I don't think I ever think of the dose of the radiation before I order a CT. If I think the CT } \\
\text { is going to give me the result, I just order it. }\end{array}$ \\
\hline \multirow[t]{3}{*}{$\begin{array}{l}\text { Strategies to minimize risk and } \\
\text { special populations }\end{array}$} & $\begin{array}{l}\text { 1. In certain populations, I think about it; I'd say I think about it more often than not in most people. In } \\
\text { certain populations, such as pediatric or women of childbearing age, I tend to think about it almost with } \\
\text { every case when dealing with abdominal, head, or chest injuries. }\end{array}$ \\
\hline & $\begin{array}{l}\text { 2. I think looking at the patient and watching them. We may watch them longer than they would be } \\
\text { watched in the adult world. We rely on the physical exam possibly more heavily than others do in other } \\
\text { places. [pediatric emergency physician] }\end{array}$ \\
\hline & $\begin{array}{l}\text { 3. I put the CT in because I assume it is better to know, but we need a better thought process that this is } \\
\text { a one-in-whatever chance that may impact management now. }\end{array}$ \\
\hline \multirow[t]{3}{*}{ Communication } & $\begin{array}{l}\text { 1. I discuss it with younger patients or women of childbearing age, usually. For all those other patients, } \\
\text { males beyond the age of } 30 \text {, women beyond the age of } 50, \text { I don't ever discuss unless they ask me } \\
\text { specifically. }\end{array}$ \\
\hline & $\begin{array}{l}\text { 2. When I have my own equipoise with respect to the risk benefit, sometimes I'Il bring the patient more } \\
\text { into the discussion than if it is a surefire thing and I really need the scan. If I'm not sure, I'Il ask the } \\
\text { patient, "We can watch and wait, or we can get some other imaging, and this is the potential risks and } \\
\text { benefits." }\end{array}$ \\
\hline & 3. I for one am much more paternalistic. If I don't think a test is needed, I won't offer it... \\
\hline Knowledge translation & $\begin{array}{l}\text { 1. A quantification of the risks that can be easily accessed and interpreted by both the clinician and } \\
\text { patient. Specific information about age-specific risks would be a priority. }\end{array}$ \\
\hline
\end{tabular}

\section{Survey development and cognitive debriefing}

Thirty-two questions were initially developed for the survey. Four questions were removed due to redundancy, and two questions were removed because they did not reflect the themes that emerged from the focus groups. Five of the remaining items were reworded for clarity. The final result was a 26-question survey (Appendix).

\section{Survey results}

The overall survey response rate was $49.8 \%$ (638 of 1,281). The mean age of respondents was $40.9 \pm 9.9$ years, and $70.7 \%$ were male. Of all respondents, $82.5 \%$ were actively practicing attending physicians and $17.0 \%$ were emergency medicine residents, and data were missing for $0.5 \%$ of respondents. Missing data included those respondents not answering questions and partially completed surveys. Of all respondents, $53.4 \%$ practiced in urban academic EDs, and the average time in practice for emergency medicine physicians was $10.7 \pm 9.6$ years. Emergency medicine resident respondents reported an average of $2.7 \pm 1.2$ years of completed training (Table 2).
Respondents were asked which imaging modalities exposed patients to ionizing radiation: radiography and CT were correctly identified by $92.2 \%$ and $95.1 \%$ of respondents, respectively. Magnetic resonance imaging (MRI) and ultrasonography were incorrectly identified as sources of radiation by $1.0 \%(n=6)$ and $0.5 \%$ $(n=3)$ of survey respondents, respectively. The LAR of malignancy due to CT in adult patients $(0.2-2 \%)$ was correctly identified by $82.2 \%$ of survey respondents, with $51.3 \%$ correctly identifying the relative LAR due to CT for children (a twofold increase). When asked which populations were at higher risk from ionizing radiation, $92.2 \%$ of respondents identified children, $80.3 \%$ identified pregnant women, and $71.4 \%$ identified women of reproductive age. Emergency physicians commonly reported appropriate risk reduction strategies, including ultrasonography or a period of observation, for scenarios involving a 26-year-old woman with suspected appendicitis and a 5 -year-old child with blunt abdominal trauma but stable vital signs. Physicians reported receiving a wide variety of questions from patients on this topic, and $27.5 \%$ reported having been asked the question, "Will this give me cancer?" When asked how often they communicated the risks associated with $\mathrm{CT}$ radiation to 
Table 2. Demographic information of survey respondents

\begin{tabular}{|c|c|}
\hline & $\begin{array}{c}\text { Total respondents to survey }=638 \\
\text { Respondents answering questions }=618(\%)\end{array}$ \\
\hline Mean age in years (SD), [range] & 40.9 (9.9) [22-69] \\
\hline Male gender, $n(\%)$ & $437(70.7)$ \\
\hline \multicolumn{2}{|l|}{ Community practice size, ${ }^{*} n(\%)$} \\
\hline$<500,000$ & $296(49.0)$ \\
\hline $500,000-1,000,000$ & $98(16.2)$ \\
\hline$>1,000,000$ & $210(34.8)$ \\
\hline \multicolumn{2}{|l|}{ Emergency department type, ${ }^{\dagger} n(\%)$} \\
\hline Academic & $340(56.4)$ \\
\hline Community (urban) & $187(31.0)$ \\
\hline Rural & 76 (12.6) \\
\hline \multicolumn{2}{|l|}{ Patient population, ${ }^{\ddagger} n(\%)$} \\
\hline Mostly or only adults & $580(96.0)$ \\
\hline Mostly or only children & $24(4.0)$ \\
\hline \multicolumn{2}{|l|}{ Physician status ${ }^{\S}$} \\
\hline Attending staff, $n(\%)$ & $510(82.5)$ \\
\hline Years in practice, mean (SD) & $10.7(9.6)$ \\
\hline Residents, $n(\%)$ & $105(17.0)$ \\
\hline Mean years of training completed (SD) & $2.7(0.2)$ \\
\hline Missing data, $n(\%)$ & $3(0.5)$ \\
\hline Excluded from survey (retired physicians, medical students), $n$ & 20 \\
\hline $\begin{array}{l}\text { *Missing data from } 14 \text { respondents }(n=604) \text {. } \\
{ }^{*} \text { Missing data from } 15 \text { respondents }(n=603) \text {. } \\
{ }^{2} \text { Missing data from } 14 \text { respondents }(n=604) \text {. } \\
{ }^{3} \text { Missing data from } 3 \text { respondents }(n=615) \text {. }\end{array}$ & \\
\hline
\end{tabular}

their patients, $37.2 \%$ answered most or all of the time, $60.8 \%$ occasionally or rarely, and $2.0 \%$ only for special populations or if asked.

\section{Knowledge translation}

Participants were asked for their preferred knowledge translation platform for future education on this topic. Respondents identified a hand-held device or smartphone application (47.9\%) or a website or Web-based calculator $(26.9 \%)$ as their preferred knowledge translation strategy to acquire, retain, and have access to information on radiation risk for their clinical practice. In addition, $90.0 \%$ of respondents felt that this topic should be core knowledge for residency training programs.

\section{DISCUSSION}

The global objective of this study was to contribute evidence toward an understanding of emergency physician knowledge of CT radiation risk and identify solutions to improve and apply new knowledge in everyday best practice. The first phase of this study identified four common themes: improving provider knowledge surrounding CT risk, clear management directives of at-risk populations, improved communication with patients about CT risk, and the need for knowledge translation. The findings of the focus groups were reinforced and validated by the responses of over 600 Canadian emergency physicians.

A majority of emergency physician respondents demonstrated considerable knowledge surrounding CT radiation dose and risk for adult patients. Most correctly identified radiography and CT as sources of ionizing radiation. Although children, pregnant women, and women of reproductive age have been identified previously as having an elevated LAR of malignancy due to $\mathrm{CT}^{21-23}$ one in two respondents were incorrect in quantifying the potential risk of CT to children. These findings are consistent with studies showing poor physician knowledge of LAR due to CT radiation exposure. ${ }^{14-16} \mathrm{~A}$ greater appreciation of these potential risks is needed. It is encouraging that strategies to reduce exposure to ionizing radiation, including ultrasonography and periods of observation, were commonly reported. Given that CT use for both 
adult and pediatric patients has increased substantially in recent years, understanding the potential risks of imaging is necessary in emergency medicine. ${ }^{1-3}$

Communication between clinicians and patients is of particular importance surrounding this topic. Previous studies reported that patients have a poor understanding of the ionizing radiation exposure associated with CT and that potential risks are rarely communicated to them. ${ }^{14,24}$ We found that approximately one-quarter of emergency physicians reported having been asked by their patients about the risks of malignancy due to CT imaging and that one-third communicated these potential risks to their patients most of the time. These rates are comparable to previous studies in which rates of 22 to $40 \%$ were reported for regular emergency medicine physician communication of these risks. ${ }^{14,16}$ This rate is likely insufficient given the documented explosion in the use of CT in emergency medicine in recent years. ${ }^{1-3,25}$

Knowledge translation is seen to be a pressing area for future research. ${ }^{26,27}$ Our survey revealed a strong desire by emergency medicine physicians and emergency medicine residents to have further education on this topic presented via medical informatics, such as Web-based modules and smart-phone applications. Previous studies have identified barriers to knowledge uptake to include practitioner time and clinician knowledge, attitudes, and skills. Previous research has also shown the utility of quick, point-of-care strategies for other physicians. ${ }^{28-31}$ Future efforts to improve point-of-care knowledge delivery to emergency medicine physicians and emergency medicine residents regarding $\mathrm{CT}$ use in the $\mathrm{ED}$ are needed.

\section{LIMITATIONS}

Our study has several important limitations. Focus group participants were recruited from four hospitals in one province; therefore, our sample may not have been representative. The original focus groups and subsequent survey were conducted in 2009 and 2010, respectively. Knowledge surrounding the risks of imaging may have increased since then, although we are unaware of any national educational interventions targeting emergency physicians in the interim. This survey was not conducted in French, and the results may not apply to French-language emergency physicians across Canada. As with any Web-based survey, our conclusions may be limited by issues of sampling, frame error, self-selection bias, and access. ${ }^{32}$ Our initial goal was to obtain participation from a majority of Canadian emergency medicine physicians and emergency medicine residents. It is possible that individuals with higher baseline knowledge or interest in this topic were more likely to respond to our survey.

\section{CONCLUSIONS}

Canadian emergency medicine physicians and emergency medicine residents demonstrated important, identifiable gaps in knowledge surrounding CT radiation dose and risk. This study identified several key areas for future physician education and some preferred modalities for knowledge translation.

Acknowledgements: We sincerely thank all of the emergency physicians and residents who participated in the focus groups, survey development, cognitive debriefing, and electronic survey. We would like to thank Drs. Eli Segal, Scott Delaney, and Michael Schull for their guidance and editorial assistance in the preparation of the manuscript.

Competing interests: None declared.

\section{REFERENCES}

1. Broder J, Warshauer DM. Increasing utilization of computed tomography in the adult emergency department, 2000-2005. Emerg Radiol 2006;13:25-30, doi:10.1007/ s10140-006-0493-9.

2. Lee J, Kirschner J, Pawa S, et al. Computed tomography use in the adult emergency department of an academic urban hospital from 2001 to 2007. Ann Emerg Med 2010;56:5916.e1, doi:10.1016/j.annemergmed.2010.05.027.

3. Broder J, Fordham LA, Warshauer DM. Increasing utilization of computed tomography in the pediatric emergency department, 2000-2006. Emerg Radiol 2007;14:227-32, doi: 10.1007/s10140-007-0618-9.

4. Larson DB, Johnson LW, Schnell BM, et al. National trends in CT use in the emergency department: 1995-2007. Radiology 2011;258:164-73, doi:10.1148/radiol.10100640.

5. Larson DB, Johnson LW, Schnell BM, et al. Rising use of CT in child visits to the emergency department in the United States, 1995-2008. Radiology 2011;259:793-801, doi:10.1148/radiol.11101939.

6. Randen A, Laméris W, Es HW, et al. Profiles of US and CT imaging features with a high probability of appendicitis. Eur Radiol 2010;20:1657-66, doi:10.1007/s00330-009-1706-x.

7. Eray O, Cubuk M, Oktay YC, et al. The efficacy of urinalysis, plain films, and spiral CT in ED patients with suspected renal colic. Am 7 Emerg Med 2003;21:152-4, doi:10.1053/ajem.2003.50027.

8. Hof KHI, Krestin GP, Steijerberg EW, et al. Interobserver variability in CT scan interpretation for suspected acute appendicitis. Emerg Med $\mathcal{f}$ 2009;26:92-4, doi:10.1136/ emj.2008.058990. 
9. Remy-Jardin M, Remy J. Spiral CT angiography of the pulmonary circulation. Radiology 1999;212:615-36, doi:10. 1148/radiology.212.3.r99se02615.

10. Berrington de Gonzalez A, Mahesh M, Kim KP, et al. Projected cancer risks from computed tomographic scans performed in the United States in 2007. Arch Intern Med 2009;169:2071, doi:10.1001/archinternmed.2009.440.

11. Smith-Bindman R, Lipson J, Marcus R, et al. Radiation dose associated with common computed tomography examinations and the associated lifetime attributable risk of cancer. Arch Intern Med 2009;169:2078-86, doi:10.1001/archin ternmed.2009.427.

12. Brenner DJ, Hall EJ. Computed tomography—an increasing source of radiation exposure. N Engl F Med 2007;357:227784, doi:10.1056/NEJMra072149.

13. Eisenberg MJ, Afilalo J, Lawler PR, et al. Cancer risk related to low-dose ionizing radiation from cardiac imaging in patients after acute myocardial infarction. CMAJ 2011;183: 430-6, doi:10.1503/cmaj.100463.

14. Lee CI, Haims AH, Monico EP, et al. Diagnostic CT scans: assessment of patient, physician, and radiologist awareness of radiation dose and possible risks. Radiology 2004;231:393-8, doi:10.1148/radiol.2312030767.

15. Shiralkar S, Rennie A, Snow M, et al. Doctors' knowledge of radiation exposure: questionnaire study. BM7 2003;327:3712, doi:10.1136/bmj.327.7411.371.

16. Keijzers GB, Britton CJ. Doctors' knowledge of patient radiation exposure from diagnostic imaging requested in the emergency department. Med 7 Aust 2010;193:450-3.

17. Frankel RM, Devers KJ. Study design in qualitative research-2: sampling and data collection strategies. Educ Health Change Learn Pract 2000;13:263-71, doi:10.1080/ 13576280050074543 .

18. Glaser BG. The discovery of grounded theory: strategies for qualitative research. Chicago: Aldine Publishing; 1967.

19. Lincoln Y. Naturalistic inquiry. Beverley Hills (CA): Sage; 1985.

20. Dillman DA. Mail and Internet surveys: the tailored design method. 2nd ed. New York: John Wiley \& Sons; 2000.

21. Griffey RT, Sodickson A. Cumulative radiation exposure and cancer risk estimates in emergency department patients undergoing repeat or multiple CT. AfR Am 7 Roentgenol 2009;192:887-92, doi:10.2214/AJR.08.1351.

22. Brenner D, Elliston $\mathrm{C}$, Hall E, et al. Estimated risks of radiation-induced fatal cancer from pediatric CT. AfR Am $\mathcal{F}$ Roentgenol 2001;176:289-96, doi:10.2214/ajr.176.2.1760289.

23. de Jong PA. Estimation of cancer mortality associated with repetitive computed tomography scanning. Am 7 Respir Crit Care Med 2005;173:199-203, doi:10.1164/rccm.200505810OC.

24. Busey JM, Soine LA, Yager JR. Patient knowledge and understanding of radiation from diagnostic imaging. Arch Intern Med 2012. DOI: 10.1001/2013.

25. Canadian Institute for Health Information. Emergency departments and children in Ontario. Available at: https:// secure.cihi.ca/estore/productFamily.htm?locale $=$ en\&pf $=$ PFC1008\&lang $=$ en\&media $=0$ (accessed January 3, 2013).

26. Lang ES, Wyer PC, Eskin B. Executive summary: knowledge translation in emergency medicine: establishing a research agenda and guide map for evidence uptake. Acad Emerg Med 2007;14:915-8, doi:10.1111/j.1553-2712.2007. tb02364.x.

27. Lang ES, Wyer P, Tabas JA, et al. Educational and research advances stemming from the academic emergency medicine consensus conference in knowledge translation. Acad Emerg Med 2010;17:865-9, doi:10.1111/j.1553-2712.2010.00825.x.

28. Kawamoto K. Improving clinical practice using clinical decision support systems: a systematic review of trials to identify features critical to success. BM7 2005;330:765, doi:10.1136/bmj.38398.500764.8F.

29. Vollmar HC, Schürer-Maly C-C, Frahne J, et al. An elearning platform for guideline implementation-evidenceand case-based knowledge translation via the Internet. Methods Inf Med 2006;45:389-96.

30. Shershneva MB, Harper PL, Elsinger LM, et al. Facilitating multiorganizational smoking cessation knowledge translation through on-line toolkit for educators and clinicians. 7 Contin Educ Health Prof 2010;30:149-50, doi:10.1002/chp. $\underline{20072}$.

31. Nagykaldi Z, Mold JW. The role of health information technology in the translation of research into practice: an Oklahoma Physicians Resource/Research Network (OKPRN) study. 7 Am Board Fam Med 2007;20:188-95, doi:10.3122/jabfm.2007.02.060084.

32. Wright KB. Researching Internet-based populations: advantages and disadvantages of online survey research, online questionnaire authoring software packages, and Web survey services. 7 Comput Mediat Commun 2006;10:00-00, doi:10. 1111/j.1083-6101.2005.tb00259.x.

\section{APPENDIX: A SURVEY OF CANADIAN EMERGENCY PHYSICIANS' AND RESIDENTS' KNOWLEDGE OF CT RADIATION DOSE AND RISK}

1. How old are you? (years)

2. Gender

1. Female

2. Male

3. Please select the description that describes your current practice situation.

1. Retired attending staff

2. Practicing attending staff

3. Resident

4. Medical student

4. In which country did you complete the majority of your medical training?

1. Canada

2. New Zealand

3. United Kingdom

4. Australia

5. South Africa 

6. United States
7. Other (please specfiy)

5. Where do you currently reside and practice medicine?
1. Canada
2. New Zealand
3. United Kingdom
4. Australia
5. United States
6. Other (please specify)

6. What is the primary language spoken at home?
1. English
2. French
3. Spanish
4. Other (please specify)

7. How many years have you been practicing emergency medicine? (not including residency/ internship)?

8. Please select the one qualification that best fits your current certification.
1. FRCP
2. CCFP
3. $\operatorname{CCFP}(\mathrm{EM})$
4. FACEP
5. FACEM
6. Other (please specify)

9. If you are a resident, how many years of postgraduate medical education/residency have you completed?

10. For the majority of your clinical duties, please select the ED type you work in.
1. Rural
2. Urban academic
3. Urban community

11. For the majority of your clinical duties, please select the population size of the community you practice in.
1. $>1,000,000$
2. $500,000-999,999$
3. $100,000-499,999$
4. $10,000-99,999$
5. $<10,000$

12. For the majority of your clinical duties, please select the setting that best describes your patient population.
1. Adult patients only

2. Pediatric patients only

3. Mostly adult patients, with some pediatric

4. Mostly pediatric, with some adults

13. Which of the following diagnostic radiology exams expose patients to ionizing radiation? (please check all that apply)
1. X-ray
2. CT
3. MRI
4. Ultrasound
5. All of the above

14. Compared to a chest $\mathrm{x}$-ray, how much radiation is received by an adult patient during a CT of the chest (i.e., to rule out pulmonary embolism)?
1. Equal
2. 2 times more
3. 50 times more
4. 300 times more
5. 1,000 times more
6. I'm not sure

15. What is the current estimate of the lifetime increased risk of cancer associated with ionizing radiation due to an abdominal CT for the average adult patient?
1. $0 \%$
2. $0.2-2 \%$
3. $5-10 \%$
4. $15-25 \%$
5. Greater than $30 \%$
6. I'm not sure

16. What is the current estimate of the lifetime relative increased risk of cancer associated with ionizing radiation due to a diagnostic CT of the abdomen for a 7-year-old boy? (compared to a 7year-old boy with no CT scan history)

1. No change

2. Double the risk

3. Four times the risk

4. Eight times the risk

5. Ten times the risk

6. I'm not sure

17. Which of the following patient populations are at a higher risk from the ionizing radiation associated with CT imaging? (please check all that apply) 
1. Pediatric

2. Pregnant women

3. Women of reproductive age

4. All of the above

18. For a 5-year-old, hemodynamically stable, blunt abdominal trauma patient, what strategies do you currently employ in your clinical practice to minimize the risk to this patient associated with CT radiation?

1. A period of observation instead of CT imaging

2. I always order a CT unless absolutely contraindicated

3. MRI

4. Ultrasound

19. For a 26-year-old, nonpregnant woman with suspected appendicitis, what strategies do you currently employ in your clinical practice to minimize the risk to this patient associated with $\mathrm{CT}$ radiation?

1. A period of observation instead of CT imaging

2. I always order a CT unless absolutely contraindicated

3. MRI

4. Ultrasound

20. Do you communicate the risks associated with CT radiation to your patients?

1. Yes, for every single CT I order

2. Yes, most of the time

3. Yes, about half the time

4. Occasionally for certain patient populations, or if the patient asks

5. No, I never do

21. If you communicate risks to your patients, please select the strategy you use most often in your clinical practice.

1. A CT scan [of X body part] is roughly equivalent to [blank] x-rays.

2. In my mind, the risk of not knowing what is going on outweighs the risk of the CT scan.
3. The studies show a roughly $\mathrm{X}$ percent increase in lifetime cancer risk due to a CT scan.

4. Other (please specify)

22. Please select questions about CT that you have received from patients or their families.

1. I have not received questions from patients about the potential risks of a CT scan.

2. Will this give me cancer?

3. Was my cancer caused by the one (or multiple) CT scan(s) I have had in the past?

4. What are the alternatives to a CT scan?

5. Why am I not getting a CT scan?

6. I had a CT last month; is another one so soon dangerous?

7. Other (please specify)

23. How often does Radiology ask you to reconsider obtaining a CT specifically due to the radiation associated with the study?

1. Never

2. Rarely

3. About half the time

4. A majority of the time

5. With every scan

24. What knowledge translation strategy would you find most helpful for acquiring, retaining, and having access to this information for your clinical practice?

1. Group learning (i.e., rounds, workshop)

2. Website or Web-based risk calculator

3. Application for hand-held device or smartphone

25. Do you think this topic should be a mandatory core knowledge component for emergency medicine residency programs?

1. Yes

2. No

26. Will this survey change your practice?

1. Yes

2. No 